\title{
Design and Testing of a Snap Load Alleviator for a Submarine Rescue Vehicle Handling System
}

\author{
Andreas Huster
}

Adrian Dayani

David Lo

Oceanworks International Corp.
North Vancouver, BC, Canada
ahuster@oceanworks.com

Abstract-The snap load alleviator (SLA) is a passive, hydraulic, shock-absorbing backup system to mitigate snap loads in a launch and recovery system for a manned submersible. The SLA is part of a mitigation strategy for potential failures identified as part of a hazard analysis. This analysis considered failures in the active heave compensation system, which is the primary approach to compensate for vessel heave in rough seas. To reduce the size and weight of the SLA, it has been designed with a much shorter stroke than the magnitude of expected vessel heave. The SLA has low inertia and mitigates only the leading edge of a snap load while the rendering function of the lift winch, which has much higher inertia, deploys additional lift line before the SLA runs out of stroke. Tight coupling of the dynamic properties of the SLA and the lift winch is required for this approach to succeed. The rationale and the design of the SLA is presented. Computer simulations demonstrate the snap loading problem and validate the proposed solution. Hardware testing to qualify the design and to corroborate the simulations is described.

\section{INTRODUCTION}

This paper describes the snap load alleviator (SLA), which has been integrated into an ROV launch and recovery system. The SLA is a passive backup system designed to mitigate excessive lift line tensions. Excessive tensions can occur in the event of failure of the primary heave compensation system during launch and recovery of a Remotely Operated Vehicle (ROV) in high sea states.

The SLA has been integrated into the US Navy's Submarine Rescue System (SRS), an air-transportable rescue system that can be mobilized on a support vessel anywhere in the world to rescue sailors from disabled submarines. The Pressurized Rescue Module (PRM), which is a manned ROV submarine with capacity for 18 occupants, is launched by an A-Frame Launch and Recovery System (LARS) near the accident site and then mates with the disabled submarine at depth to allow the transfer of sailors to the rescue submarine. Figure 1 presents a rendering of the SRS mounted on the stern of a vessel, as seen from the starboard aft.

The LARS uses a single lift line, double reeved through the cursor frame, which is mechanically coupled to the PRM. There are two lift winches, one mounted on the side of each of the A-Frame legs. For each lift winch, the lift line runs up the side of the leg, along the cross beam, and down to the cursor.

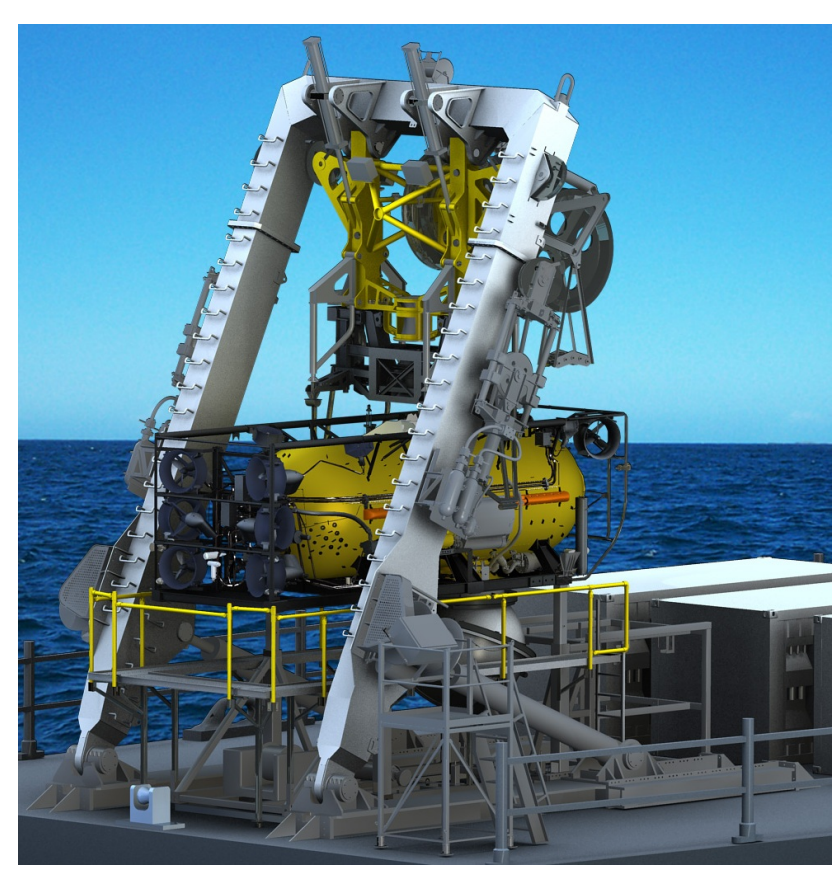

Fig. 1. Rendering of the Submarine Rescue System showing the PRM, the A-Frame LARS, and the Starboard SLA

During normal operation, an active heave compensation system uses various sensor measurements to compute the ideal lift winch motion in order to cancel the heave motion of the support vessel in heavy seas of up to sea state 4 . When operating properly, this primary system achieves near constant lift line cable tension. Constant tension eliminates slack lift lines and the resulting snap loads. However, active systems are susceptible to various failures (e.g., mechanical and hydraulic failures, sensor failures, loss of power, control system errors). A failure in the active heave compensation system can lead to slack lines and snap loads that are in excess of the LARS load rating. Consequently, the SLA was designed to mitigate excessive lift line tensions in order to protect the LARS during failures of the active heave compensation system.

The SLA consists of two sheaves, a hydraulic cylinder and two accumulators (see Figure 2). The lift line is wrapped around both sheaves. The top sheave is stationary and is 


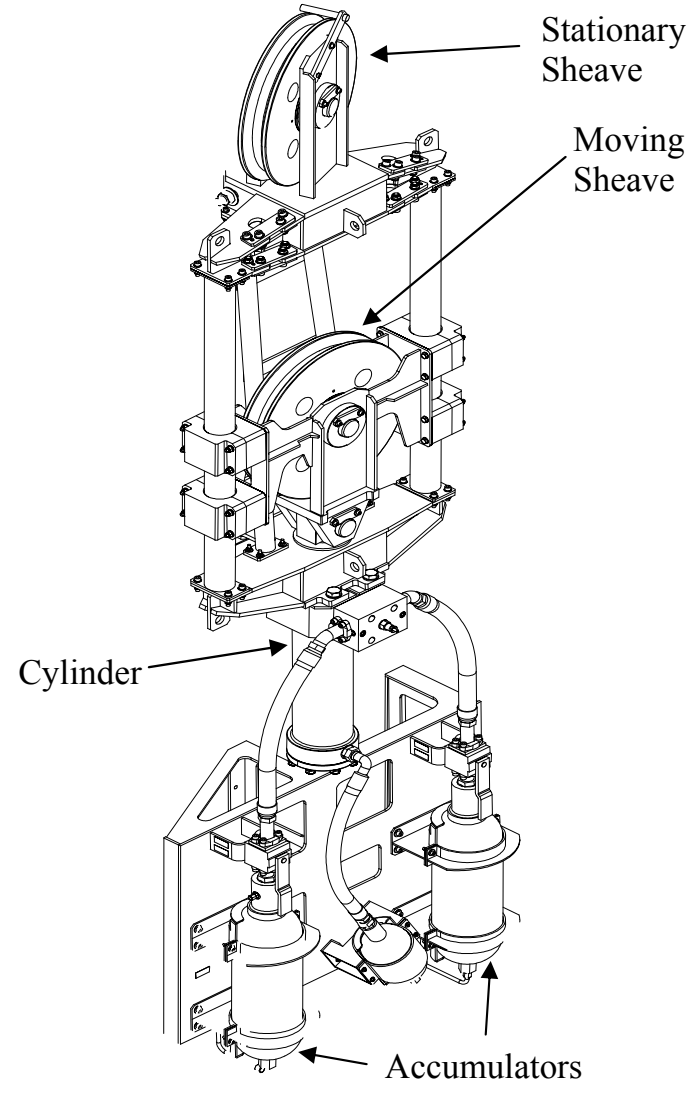

Fig. 2. Model of the Snap Load Alleviator

attached via a rigid frame to the bore of a hydraulic cylinder. The bottom sheave is a moving sheave that is attached to the cylinder rod. Large lift line tensions pull the moving sheave up towards the stationary sheave. This action deploys a small amount of lift line at the correct speed, which smooths the impact load on the lift line during the cable snap and reduces the load to acceptable levels. Two SLAs are included in the LARS, one on the side of each A-Frame leg. The SLA on the starboard leg is visible in Figure 1.

The initial design of the LARS did not include the SLA. However, following an incident with a similar system operated by the Royal Australian Navy at the Black Carillion exercise in 2004, where its LARS A-Frame suffered cracking due to excessive lift line loading, a hazard analysis was performed on the US Navy SRS LARS. This hazard analysis indicated that single failures in the heave compensation system could lead to excessive snap loads. The design of the mitigation strategy faced unique constraints because it had to be integrated easily within the existing design and fit within the remaining weight budget. The size and weight of the SLA was reduced to acceptable levels by splitting the snap load mitigation function between the SLA and the passive rendering capability of the lift winches. The hydraulic winches render, or unspool, when the load induced pressure in the winch motor cracks a relief valve. Rendering of the winches is an important feature to protect the LARS, but rendering on its own does not occur fast enough to avoid excessive snap loads due to the high inertia of the lift winches.

The SLA, which has comparatively low inertia but only a small amount of lift line take-up, is responsible for the initial mitigation of the snap load, providing time for the high-inertia lift winches to speed up and mitigate the snap load through the full vessel heave excursion. Coordinating the dynamic performance of the SLA with the properties of the lift winches was essential to achieving a successful design.

The lift winches can operate in two different modes. The first is the high-torque/low-speed mode, which is used to lift the PRM and cursor in air. The second is the low-torque/highspeed mode, which is used for heave compensation of the PRM and cursor when they are submerged and substantially lighter than in air. The combination of SLAs and rendering of the lift winches works to alleviate excessive snap loads only if the winches are in the low-torque mode. In the hightorque mode, the winches will also render, but at a much higher tension that is too close to the lift line load limit. This is not a limitation because snap loads are only a problem when the PRM is in the water and can be supported in low-torque mode. Thus, inadvertent operation of the winches in hightorque mode when the PRM is submerged is considered a failure.

The design process for the SLA relied heavily on dynamic simulations of snap loads through the system. These simulations were used to demonstrate the requirement for a passive backup system, to explore the effect of various high-level design choices, to determine the performance requirements of the mechanical system, and finally, to verify that the designed system would in fact mitigate excessive snap loads.

To build confidence in the simulations, the SLA was instrumented and tested under maximum rated load conditions. During this test, the SLA was subjected to realistic snap loads - the load was generated by a cart weighing $54,450 \mathrm{lbs}$ travelling down an incline at upwards of $11.6 \mathrm{ft} / \mathrm{s}$. This qualification test provided the necessary data to validate the simulations and to tune the damping parameters of the SLA. During this testing, orifices of various sizes were inserted into the hydraulic fluid flow to achieve the desired damping parameters.

\section{A. Overview}

The paper is structured as follows: Section II provides background information on the active heave compensation capability and the susceptibility of the system to snap loads during potential failures of active heave compensation. This includes a description of the computer simulation used to predict the severity of potential snap loads. Section III describes the design of the SLA, including the concept design, the differential equations used to model the SLA and the parameters in that model. Section IV provides simulation results that show that the SLA design is able to reduce the magnitude of snap loads below the 54,265 lbf load rating. Finally, Section V describes hardware-based qualification testing of the SLA that verifies the dynamic performance of the SLAs. 


\section{BACKGROUND}

\section{A. Heave Compensation}

The tension on the lift line is typically managed by an active heave compensation system. This is a computer-controlled system that matches the length of the deployed lift line to the current vessel-to-PRM separation. The active heave compensation system uses sensor measurements of the lift line tension, lift line pay-out, heave acceleration of the surface vessel, and feedback from the hydraulic system to compute the desired lift winch motion. The control objective is to maintain near-constant tension on the lift line while accommodating the substantial vessel heave motion that is observed during higher sea states.

The advantages of active, winch-based heave compensation are two-fold. First, an active system can incorporate vessel accelerations as lead information to predict heave motion and can achieve higher performance. Second, a winch-based system incurs no additional weight and space apart from additional sensors, cables and computers. A key disadvantage of an active, winch-based system is that it has significant complexity and relies on the correct operation of many of the following components distributed throughout the LARS:

- sensors, actuators and computers (including cables, connectors and junction boxes)

- control software and operating systems

- hydraulic pumps, motors, hoses, valves

- electric supply power, power distribution, electric pump motors and motor controllers

- operator actions

Therefore, various failures of the LARS can compromise the ability of the active heave compensation system to manage the lift line tension. A failure of the active heave compensation system can lead to snap loading and excessive lift line tension.

The US Navy SRS is more susceptible to snap loading than typical ROV systems for several reasons:

- The PRM, when considering added mass and entrained water, has a very large mass. The PRM also has large drag coefficients in the vertical direction. Thus, large tension forces are required to accelerate the PRM through the water column.

- The PRM is a large submersible that is buoyant in water. Together with the cursor frame, the weight of the PRM and cursor in water is low compared to its mass and drag. Therefore, if the lift lines become slack during a downward heave motion of the support vessel, the PRM will not easily sink to take up that slack. Thus, the lift lines are likely to become taut while the support vessel is heaving up at a high speed, causing the resulting snap load to have a larger magnitude.

- The A-Frame and all other structural items are modular and air-transportable. They have been optimized for weight and do not have additional load capacity beyond that required for normal operation. Thus, even small snap loads can exceed the load rating.
This susceptibility to excessive snap loads triggered the more comprehensive analysis of the problem described below.

\section{B. Simulation of Snap Loads}

This section presents simulation results for several potential failure mode states of the LARS. Computer simulations were performed to determine the effect of sea state induced vessel motion on the dynamic response of the PRM and various components of the LARS. This simulation was computed using the MATLAB software package. These simulations indicate that excessive snap loads can result from many different system failures. These findings are the basis for the requirement to mitigate snap loads due to potential system failures.

The dynamic simulations are based on a model of the system described in [1] and a controller described in [2]. The model is based on lumped parameters to capture various aspects of the system, like inertia, drag, damping, friction, compliance, response times and hydraulic flow through pumps, motors and various valves. The details of this model are beyond the scope of this paper.

During each simulation, the vessel is assumed to heave according to a sine wave profile with period 6.07 seconds and peak velocity $11.6 \mathrm{ft} / \mathrm{s}$. These are worst-case conditions for the motion at the top of the A-Frame when it is mounted on a typical vessel during sea state 4 conditions. Each simulation is $30 \mathrm{~s}$ in length. For the first $10 \mathrm{~s}$, the system is operating normally. At $10 \mathrm{~s}$, the failure mode is triggered. The effect of this failure mode can then be observed for the following $20 \mathrm{~s}$.

Four classes of failures were considered for this analysis. Each failure could be applied to either one or both winches. The four failures are:

1) Brake Applied: Inadvertent application of the winch brake due to operator error or loss of hydraulic power.

2) Loss of Active Heave Compensation: Failures of the control computer, sensors, or actuators resulting in no active winch motion.

3) High-Torque Mode: Inadvertent switch to high-torque mode while the PRM is in the water, due to operator error or system failure.

4) Out-Of-Phase Heave Compensation: Error in the active heave compensation capability that causes it to act in a counter-productive manner.

Graphical results are provided for the loss of active heave compensation on both winches. Position and tension plots are shown. Figure $3 \mathrm{a}$ shows the motion of the vessel, the submersible, and one of the winches (both winches perform similarly). Figure $3 b$ shows the lift line tension. Complete results for all failure modes are provided in [3].

On the position plot, a vertical line at $10 \mathrm{~s}$ indicates the beginning of the failure. Small vertical bars at the bottom of the figure indicate the presence of a snap load. The positions of the vessel, submersible, and winches are all initialized such that they average to zero when the control system is working. The winch positions have been converted to an equivalent length of lift line. 


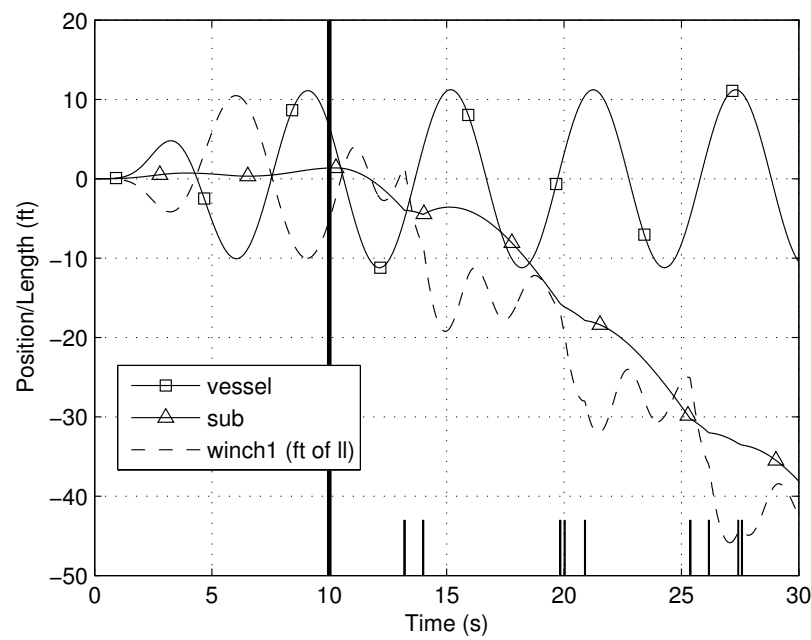

(a) Positions and Lift Line Length

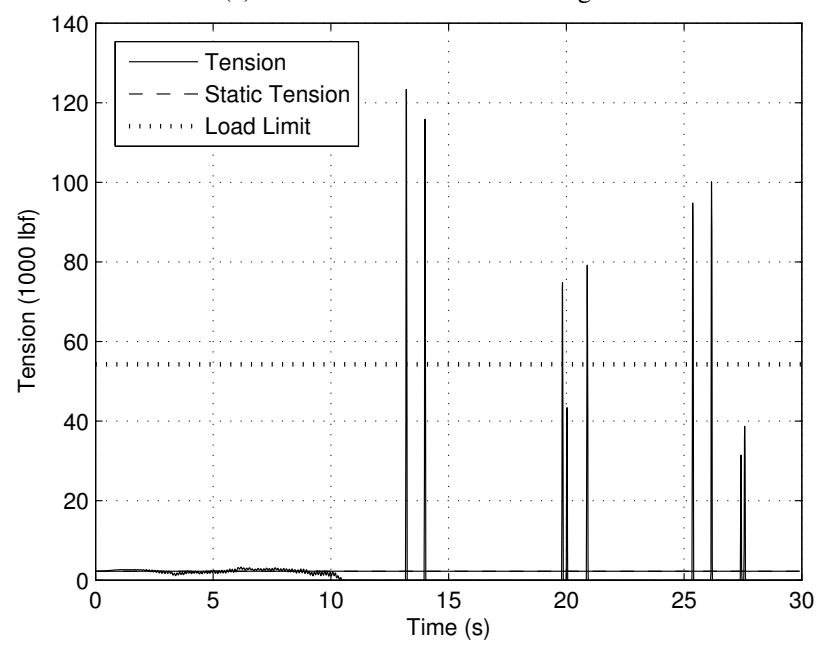

(b) Tension

Fig. 3. Dynamic simulation of a loss of heave compensation at $10 \mathrm{~s}$, before implementing mitigations

In addition to the tension, the second plot shows two reference levels. The first is the static tension, which is due to the PRM and cursor weight in water. The second is the lift line load limit.

The maximum tension results from these simulations are tabulated in Table I. The table shows that in all eight cases, the magnitude of the largest potential snap load is greater than the maximum allowable tension of 54,265 lbf. Thus, a snap load mitigation strategy for failures of the heave compensation system was required.

\section{Options for Snap Load Mitigation}

The adopted strategy for mitigating excessive snap loads includes several parts:

1) Two SLAs, one on each A-Frame leg. The purpose of the SLA is to provide a fast, low-inertia mechanism to deploy a short amount of lift line while the lift winches render and accelerate up-to-speed.

2) An operational requirement to maintain the winches in
TABLE I

Summary of Simulation Results Without Mitigations. The LifT LINE LOAD LIMIT IS $54,265 \mathrm{lbf}$

\begin{tabular}{|c|l|r|}
\hline Case & Failure & Max Tension (lbf) \\
\hline \hline 1 & Both Brakes Applied & 281,000 \\
\hline 2 & One Side Brake Applied & 102,000 \\
\hline 3 & No Active Compensation & 123,000 \\
\hline 4 & One Side Active Compensation & 91,000 \\
\hline 5 & High Tension Mode in Water & 126,000 \\
\hline 6 & One Side High Tension Mode & 64,000 \\
\hline 7 & Both Sides Out-Of-Phase & 230,000 \\
\hline 8 & One Side Out-Of-Phase & 125,000 \\
\hline
\end{tabular}

low-torque mode whenever the PRM is submerged. The winches do not render quickly enough in high-torque mode.

3) A design change to hold open the winch brakes even when hydraulic power is lost, if the winches are in lowtorque mode. This change ensures that the rendering capability of the winches, which is essential for complete mitigation of snap loads, is retained.

Taken together, this strategy mitigates all eight failure mode states described in Table I.

Other alternatives for mitigating snap loads were considered. A full-sized, passive heave compensation capability that does not require rendering of the lift winches was an option. However, this alternative is too large and heavy and could not have been integrated into the existing design. A simple shear mechanism could have been added to separate the PRM from the cursor during excessive lift line tensions. But this option was considered too risky for a man-rated system.

\section{SLA DESIGN}

\section{A. SLA Concept}

Figure 4 shows a functional representation of the SLA. The SLA has two sheaves, one stationary and one moving. The moving sheave is attached to the rod of a hydraulic cylinder. The cylinder has a piston area $A_{C}$ and a stroke length $S_{C}$ and is filled with a volume of hydraulic fluid $V_{C}$ at pressure $p_{C}$. Attached to the rod end of the cylinder is an accumulator with a nitrogen-filled gas bladder. The pressure and volume of the gas bladder are $p_{A}$ and $V_{A}$. The cap-end of the cylinder is filled with nitrogen. As the lift line tension $T$ is increased, the moving sheave is pulled up towards the stationary sheave. The position of the moving sheave is $x_{s l a}$ and $x_{s l a}=0$ when the cylinder is completely retracted. As $x_{s l a}$ increases, fluid is pushed into the accumulator, which compresses the gas bladder and causes the fluid pressure to rise, thus creating a restoring force. The fluid flows into the accumulator through an orifice that causes a drag $B_{\text {sla }}$.

The accumulator is pre-charged with a known volume of gas $\bar{V}_{A}$ at pressure $\bar{p}_{A}$ such that the moving sheave begins to move only if the lift line tension increases beyond a large threshold. As shown in Figure 2, the SLA actually has two accumulators. These are identical and are plumbed in parallel 


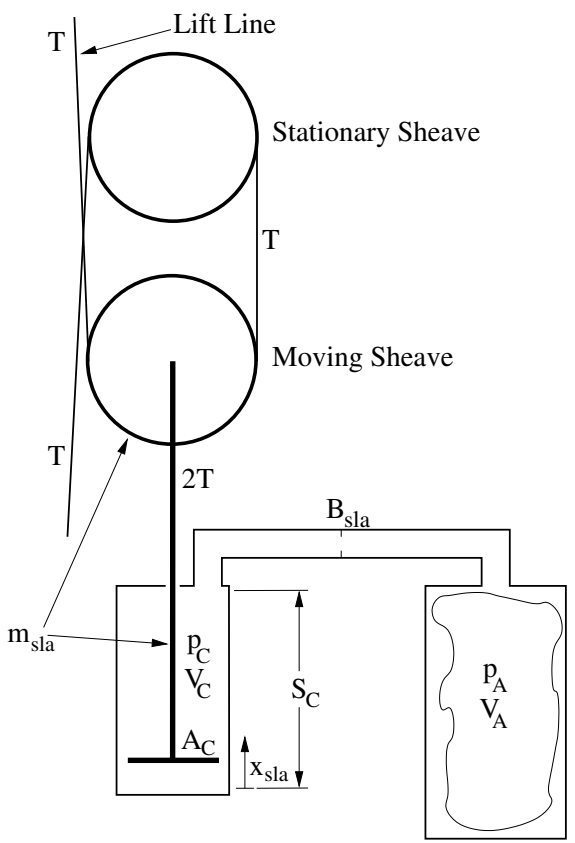

Fig. 4. Functional Representation of the Snap Load Alleviator

for manufacturing purposes, but are functionally equivalent to one large accumulator, as depicted in Figure 4.

\section{B. Dynamic Model of the SLA}

The moving sheave and cylinder rod are subject to twice the lift line tension as well as the restoring force, $F_{\text {sla }}$, generated within the hydraulic cylinder, as shown in Equation 1.

$$
m_{\text {sla }} \ddot{x}_{\text {sla }}=2 T-F_{\text {sla }}\left(x_{\text {sla }}, v_{\text {sla }}\right)
$$

$m_{\text {sla }}$ is the total moving mass, which includes the sheave (including mounting hardware), the cylinder rod and a volume of hydraulic fluid. $F_{\text {sla }}$ is described by Equation 17.

$F_{\text {block }}\left(x_{\text {sla }}\right)$ captures the large, non-linear forces that prevent the piston and sheave from moving beyond the mechanical limits imposed by the cylinder. $F_{\text {block }}$ can be used to isolate the hydraulic component of $F_{\text {sla }}$ in Equation 1.

$$
2 T+F_{\text {block }}\left(x_{\text {sla }}\right)=m_{\text {sla }} \ddot{x}_{s l a}+A_{C} p_{C}
$$

The volume of fluid in the cylinder is the initial volume reduced by any motion of the piston. Because the fluid is not compressible, a similar relationship exists for the nitrogen volume in the accumulator.

$$
\begin{aligned}
V_{C} & =A_{C}\left(S_{C}-x_{s l a}\right) \\
V_{A} & =\bar{V}_{A}-A_{C} x_{s l a} \\
\dot{V}_{C} & =\dot{V}_{A}=-A_{C} \dot{x}_{s l a}
\end{aligned}
$$

The accumulator nitrogen pressure and volume are related by
Boyle's Law.

$$
\begin{aligned}
\bar{p}_{A} \bar{V}_{A} & =p_{A} V_{A}=p_{A}\left(\bar{V}_{A}-A_{C} x_{\text {sla }}\right) \\
p_{A} & =\frac{\bar{p}_{A} \bar{V}_{A}}{\bar{V}_{A}-A_{C} x_{\text {sla }}} \\
& =\frac{\bar{p}_{A}}{1-\frac{A_{C}}{V_{A}} x_{s l a}}
\end{aligned}
$$

The differential pressure between the cylinder and the accumulator depends on the fluid flow.

$$
\begin{aligned}
p_{C}-p_{A} & =-B_{\text {sla }} \dot{V}_{C}=B_{\text {sla }} A_{C} \dot{x}_{\text {sla }} \\
p_{C} & =B_{\text {sla }} A_{C} \dot{x}_{\text {sla }}+\frac{\bar{p}_{A}}{1-\frac{A_{C}}{\bar{V}_{A}} x_{\text {sla }}}
\end{aligned}
$$

where $B_{\text {sla }}$ is the drag parameter in units of pressure/flow. Substituting for $p_{C}$ in Equation 2 leads to the equation of motion for the SLA.

$$
\begin{aligned}
2 T+F_{\text {block }}\left(x_{\text {sla }}\right)= & m_{\text {sla }} \ddot{x}_{\text {sla }}+A_{C}^{2} B_{\text {sla }} \dot{x}_{\text {sla }} \\
& +\frac{\bar{p}_{A} A_{C}}{1-\frac{A_{C}}{V_{A}} x_{s l a}}
\end{aligned}
$$

During the initial movement of the piston, the volume of fluid displaced is much smaller than the accumulator nitrogen volume $\left(A_{c} x_{\text {sla }} \ll \bar{V}_{A}\right)$, so this equation can be linearized with a first-order Taylor series expansion. This linearization is useful for approximating the effective spring constant and damping factor.

$$
\begin{aligned}
& F_{\text {applied }} \cong m_{\text {sla }} \ddot{x}_{\text {sla }}+b_{\text {sla }} \dot{x}_{\text {sla }}+k_{\text {sla }} x_{\text {sla }} \\
& \text { where: } \\
& F_{\text {applied }}=2 T+F_{\text {block }}\left(x_{\text {sla }}\right)-\bar{p}_{A} A_{C} \\
& k_{\text {sla }}=\frac{\bar{p}_{A} A_{C}^{2}}{\bar{V}_{A}} \\
& b_{\text {sla }}=A_{C}^{2} B_{\text {sla }} \\
& \zeta_{\text {sla }}=\frac{b_{\text {sla }}}{2 \sqrt{k_{\text {sla }} m_{\text {sla }}}}
\end{aligned}
$$

$b_{s l a}$ expresses damping in units of force/speed. $\zeta_{s l a}$ is the damping factor.

$F_{s l a}$ is then written such that Equation 1 and Equation 11 are equivalent.

$$
\begin{aligned}
F_{\text {sla }}\left(x_{\text {sla }}, v_{\text {sla }}\right)= & b_{\text {sla }} v_{\text {sla }}+\frac{\bar{p}_{A} A_{C}}{1-\frac{A_{C}}{\bar{V}_{A}} x_{\text {sla }}} \\
& -F_{\text {block }}\left(x_{\text {sla }}\right)
\end{aligned}
$$

\section{Simulation of Snap Loads with the SLA}

To assess the effectiveness of the SLA design, the simulation described in Section II-B has been expanded with the dynamic model of the SLA. Two SLAs, one on each side of the AFrame, have been added to the simulation. The new simulation was used in an iterative fashion to determine suitable design parameters and to compute snap load simulation results that include the SLAs. 


\section{Design Constraints and Parameter Choices}

The simulation environment described above was used iteratively to evaluate various design choices. This section reports the findings of this iterative process.

1) Cylinder Area: The rod-side area of the cylinder piston was selected to ensure reasonable hydraulic pressures during maximum lift line tension. The cylinder has a $7 \mathrm{in}$ bore and a $3 \mathrm{in}$ rod, leading to a piston area of $A_{C}=31.4 \mathrm{in}^{2}$. The corresponding maximum tension is computed from the maximum allowable lift line tension $\left(T_{\max }\right)$ and the piston area.

$$
\begin{aligned}
p_{C, \max } & =2 T_{\max } / A_{C} \\
& =2(54,265 \mathrm{lbf}) / 31.4 \mathrm{in}^{2} \\
& =3,450 \mathrm{psi}
\end{aligned}
$$

2) Breakout and Contracted Forces: A key difference between the SLA and a full passive heave compensation system is the lift line tension required to move the sheave. The SLA is based on a break-out force that is five times the nominal line tension when the PRM is in water. Therefore, the SLA begins to move only when the line tension increases above normal loads as a result of failure.

This approach has three advantages. First, the SLA does not interfere with the response of the active heave compensation system. Second, the full amount of lift line take-up is available when the system experiences a snap load. Third, during the initial moments of a snap load, the maximum tension is transmitted to the winch to promote fast rendering of the winch, which is the effect that ultimately relieves the snap load.

Further, the system is designed to be completely contracted when the PRM is lifted out of the water. This prevents any motion of the SLA while the PRM is lifted in air. The tension force required to fully contract the SLA is designed to be $80 \%$ of the nominal in-air tension, which keeps the SLA contracted even when the vessel experiences downward heave accelerations that are typical for sea state 4 .

The weight of the PRM and cursor in air is $W_{A i r}=$ $50,710 \mathrm{lbs}$. The equivalent force on the cylinder piston is $F_{A i r}=2 T_{A i r}=W_{A i r}$. The force necessary to contract the SLA fully should therefore be

$$
\check{F}_{A}=80 \%\left(F_{\text {Air }}\right)=40,570 \mathrm{lbf}
$$

Finally, the steady-state accumulator pressure when the SLA is fully contracted is

$$
\check{p}_{A}=\check{F}_{A} / A_{C}=1292 p s i .
$$

The net weight of the PRM and cursor in water is $W_{\text {Water }}=4,500 \mathrm{lbs}$. This corresponds to an SLA cylinder pressure of $143 \mathrm{psi}$. The breakout pressure was chosen to be about five times greater at

$$
\bar{p}_{A}=750 p s i
$$

3) Damping vs. Cylinder Stroke: The remaining compromise is between cylinder stroke, $S_{C}$, and the damping parameter, $B_{\text {sla }}$. If damping is too low, then the moving sheave will accelerate too quickly, reaching the end of its stroke before the lift winches have accelerated sufficiently. If the damping parameter is too high, the SLA will not accelerate quickly enough and the lift line tension will be too high.

Simulations were used to identify a suitable compromise at $B_{\text {sla }}=65.7 \frac{\mathrm{psi}}{\mathrm{gal} / \mathrm{s}}$ and $S_{C}=22 \mathrm{in} . S_{C}$ is $25 \%$ larger than necessary and the maximum simulated lift line tension is about $20 \%$ below $T_{\max }$. These margins provide contingencies against model errors and manufacturing tolerances.

4) Dependent Parameters: The remaining parameters are constrained by the free parameters chosen above. They are:

$$
\begin{aligned}
m_{\text {sla }} & =595 \mathrm{lbs} \\
\bar{V}_{A} & =\check{p}_{A} A_{C} S_{C} /\left(\check{p}_{A}-\bar{p}_{A}\right) \\
& =7.2 \mathrm{gal} \\
k_{\text {sla }} & =447 \mathrm{lbf} / \mathrm{in} \\
b_{\text {sla }} & =281 \frac{\mathrm{lbf}}{\mathrm{in} / \mathrm{s}} \\
\zeta_{\text {sla }} & =5.35
\end{aligned}
$$

\section{Simulation Results}

This section presents simulation results of the system with both SLAs included. The objective of the SLA is to mitigate excessive snap loads that are generated for the six failure mode states that include Cases 2, 3, 4, 6, 7 and 8. Detail results are presented for Case 3. Results for these six cases are summarized in Table II. Case 1 is eliminated by a design change that holds the brakes open in low-torque mode. Case 5 is eliminated by always operating the winches in low-torque mode while the PRM is submerged. This is handled by specific operator training.

Figures 5 and 6 show the results of the simulation for Case 3. During the first ten seconds of the simulation, the system behaves normally, with the lift winches compensating for vessel heave. At $10 \mathrm{~s}$, the failure occurs and remains active for the remainder of the simulation. A vertical line at $10 \mathrm{~s}$ indicates the start of the failure.

Figure 5a shows the position of the vessel, submersible, winch, and both SLA sheaves. Snap loads are indicated by the vertical bars at the bottom of this plot. Figure 5b shows the lift line tension. The plot shows that the lift line tension never exceeds the load limit, even in the presence of snap loads.

The position plot looks very similar to the unmitigated case on Figure 3a. This is consistent with the design of the SLA, which has small sheave motion and motion only during and immediately after a large snap load. This small contribution of the SLA is sufficient to lower the snap load peaks in the tension plot to below the load limit.

Figures $6 \mathrm{a}$ and $6 \mathrm{~b}$ show in greater detail the sheave motion during a snap load (extracted from a different failure mode state). The velocity profile indicates a very fast speed increase 


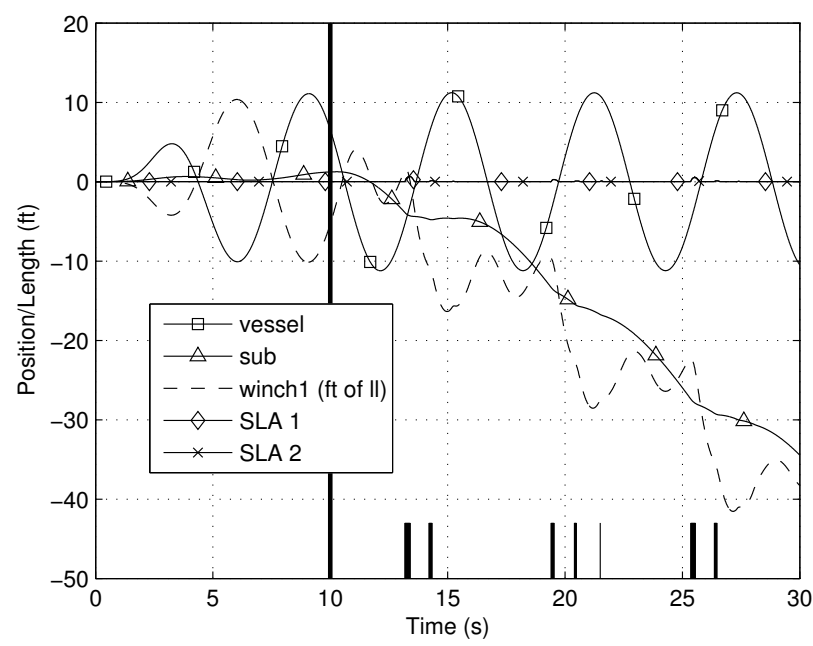

(a) Position and Lift Line Length

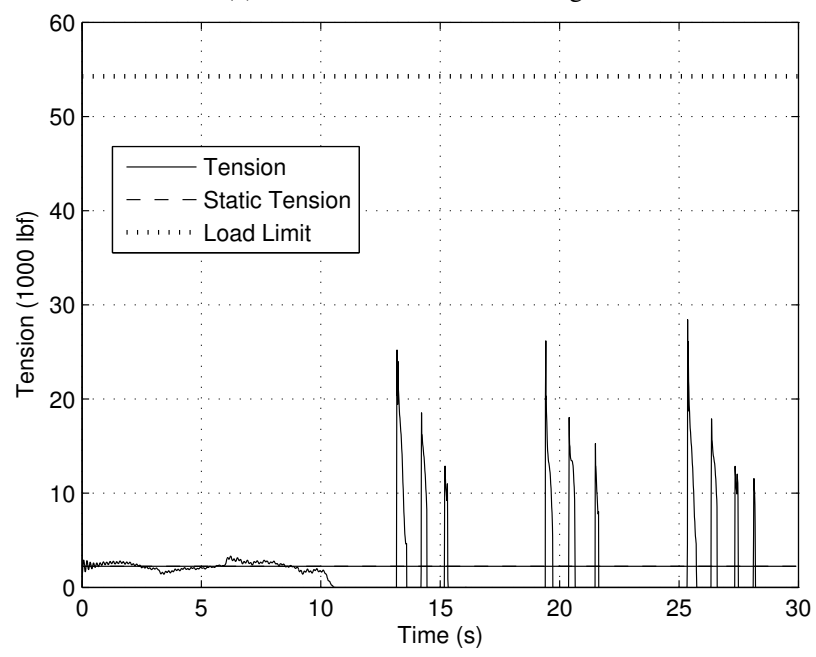

(b) Tension

Fig. 5. Dynamic simulation of a loss of heave compensation at $10 \mathrm{~s}$, with one SLA on each side included

at the leading edge of the snap load, which is consistent with the high forces during the snap load and the relatively low SLA inertia. However, the damping generated by the hydraulic fluid reduces the sheave velocity as soon as the lift line tension drops. Following the snap load, the restoring force generated by the accumulator fully retracts the moving sheave, in anticipation of the next potential snap load.

Table II summarizes the results for the six remaining failure mode states. For each case, the table lists the maximum line tension and the largest SLA excursion computed by the simulation. These results confirm that the SLA successfully reduces the maximum lift line tension below the load limit of $54,265 \mathrm{lbf}$ in all cases and that the SLA never reaches full stroke.

\section{Qualification Testing}

Qualification testing was performed on the SLA to tune the design and to demonstrate its effectiveness. This section describes the test objectives, test setup, acceptance criteria and

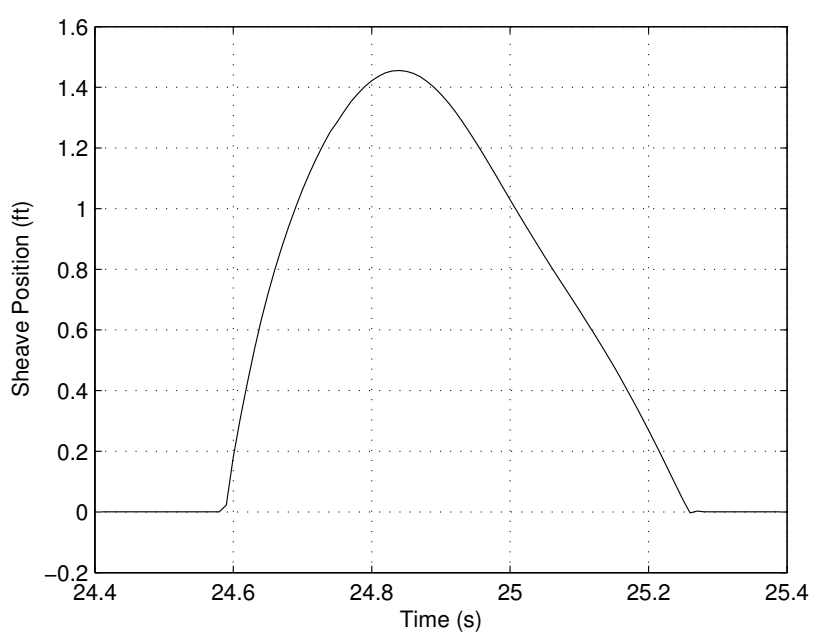

(a) Position

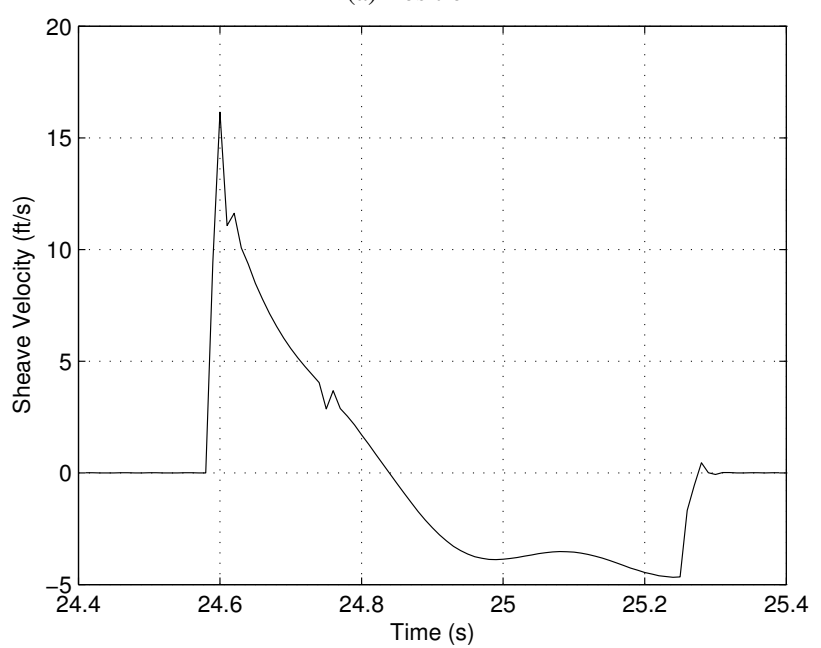

(b) Velocity

Fig. 6. Detail of the position and velocity of the SLA sheave for a typical snap load

TABLE II

Summary of Simulation Results With SLAS INCLUdED

\begin{tabular}{|c|l|c|c|}
\hline Case & Failure & $\begin{array}{c}\text { Max } \\
\text { Tension } \\
\text { (lbf) }\end{array}$ & $\begin{array}{c}\text { Max SLA } \\
\text { Excursion } \\
\text { (in) }\end{array}$ \\
\hline \hline 2 & One Side Brake Applied & 16,000 & 2.7 \\
\hline 3 & No Active Compensation & 28,000 & 8.0 \\
\hline 4 & One Side Active Compensation & 22,000 & 4.9 \\
\hline 6 & One Side High Tension Mode & 20,000 & 7.3 \\
\hline 7 & Both Sides Out-Of-Phase & 43,000 & 17.5 \\
\hline 8 & One Side Out-Of-Phase & 33,000 & 12.7 \\
\hline
\end{tabular}




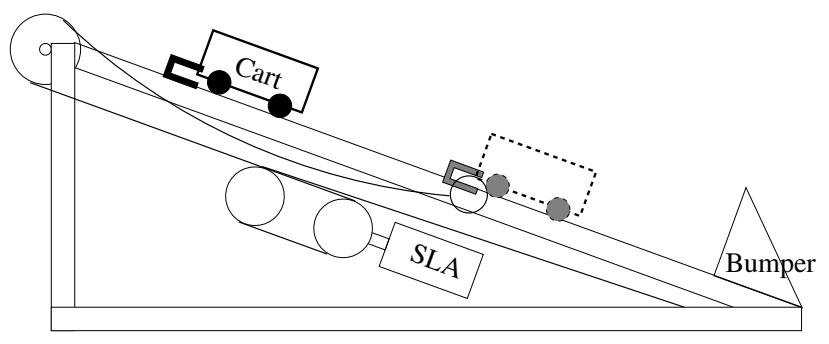

Fig. 7. Test Ramp for the SLA Qualification Test

test results.

The SLA was tested before the LARS system was integrated and was tested without the matching lift winches. The dynamic properties of the SLA were therefore evaluated without winch rendering. This affects how the acceptance criteria were written.

\section{A. Test Objectives}

Qualification testing was performed to ensure that the actual dynamic performance of the SLA matched, within reasonable variations, the assumed performance in the above simulations. This is important for the following reasons:

1) The dynamic performance is key to the function of the SLA, which is to provide a damped, low-inertia release of lift line at the onset of a snap load.

2) The dynamic performance of the SLA is difficult to predict using only a mathematical simulation. This is due to the impulsive forces associated with snap loads and the difficulty in modelling hydraulic pressures through restricted flow paths.

\section{B. Test Setup}

Figure 7 shows a sketch of the test setup for the SLA qualification test. A large ramp was constructed which was used to accelerate a weighted cart. The cart was designed to pick up a cable near the bottom of the ramp. This cable ran across a sheave at the top of the ramp, was then reeved through the SLA mounted underneath the ramp and anchored to a fixed point on the ramp frame.

The actual weight of the cart was $54,450 \mathrm{lbs}$, which is slightly larger than the inertia that the SLA is expected to experience when it is used to mitigate snap loads. This corresponds to the mass of the PRM, the cursor, the added mass, and the entrained water, divided by two because the total inertia is spread across both lift lines.

For each test, the cart was released at the top of the ramp. The cart then accelerated toward the bottom of the ramp (due to the force of gravity) until it picked up the cable and was decelerated by the SLA. The bumper at the bottom of the ramp stopped the cart before the end of the SLA stroke. The initial height of the cart was $10.5 \mathrm{ft}$ along the ramp. This value was determined to lead to the desired $11.6 \mathrm{ft} / \mathrm{s}$ cart velocity when the cart engaged the SLA.

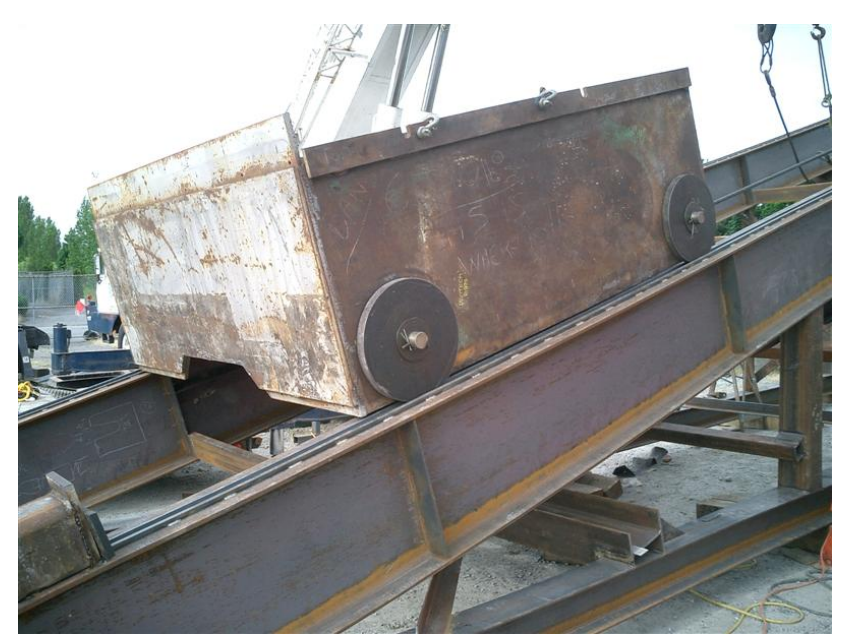

(a) Test Ramp and Cart

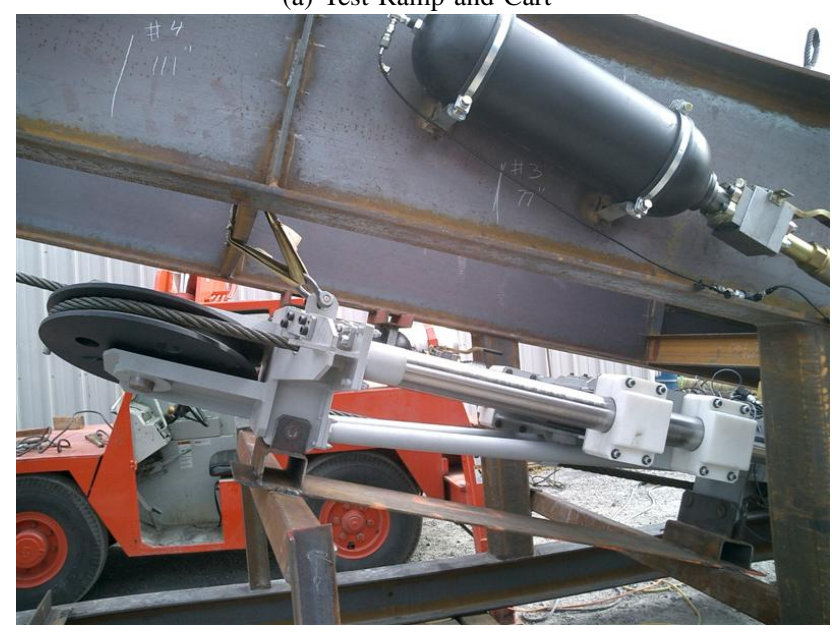

(b) SLA Installed Underneath the Ramp

Fig. 8. Photos of the Test Setup for the SLA Qualification Test

\section{Acceptance Criteria}

The acceptance criteria are written for qualification of the SLA design, as tested without a lift winch. The acceptance criteria accommodate that this test setup has reduced mitigation capability relative to the integrated LARS, where the SLAs work in conjunction with the lift line winches. The requirements for the SLAs in the integrated LARS are that for the given sea state 4 vessel characteristics and during a heave compensation failure, the line tension does not exceed the lift line rating of 54,265 lbf and the SLAs do not reach the end of stroke. This requires that the SLA has specific damping parameters that are tied to its mass, its effective spring constant, the inertia and rendering properties of the winch, and the inertia of the PRM.

During the initial impact (i.e., the first $0.05 s$ of a snap load), the highest lift line tensions are observed. This is also the phase in which the lift winches (in the integrated LARS) tend not to participate in alleviating the snap load as their inertia is too high. Thus, the maximum tension requirement for the integrated LARS is transferred directly to the SLA qualification test. 
Shortly after the initial snap, the lift winches accelerate sufficiently to reduce the overall lift line tension and to reduce the required SLA speed, allowing the SLA to retract before it reaches its end of stroke. This was not the case during the SLA qualification test, because no winches were present. Instead, the cart was stopped by the bumper just before the SLA reached its end of stroke. The end-of-stroke requirement is therefore replaced by a velocity reduction requirement.

1) Line Tension:

REQUIREMENT: The line tension shall not increase above the system rating of $54,265 \mathrm{lbf}$.

RATIONALE: The largest tension forces occur during the initial impact, when the conditions are similar with and without the winch present. Subsequent tension tends to decrease, even without the winch present. This is a conservative requirement as the tensions are expected to be lower with a winch present.

2) Rod-End Pressure:

REQUIREMENT: The rod-end pressure of the cylinder does not increase above 3000 psi.

RATIONALE: All of the components of the SLA have been designed to a maximum operating pressure of $3000 \mathrm{psi}$. The pressure at the rod-end of the cylinder will be the largest. This is a conservative requirement, as the pressure, just like the tension, is expected to be lower with the winches present.

3) Velocity at Full Stroke:

REQUIREMENT: The velocity of the cart at full cylinder stroke shall be reduced by at least $2 \mathrm{ft} / \mathrm{s}$ from the initial cart velocity.

RATIONALE: This requirement ensures that the SLA provides sufficient damping. Greater damping leads to a greater reduction of cart speed, but higher line tension. In the integrated LARS configuration (with the winches included), insufficient SLA damping and insufficient line tension causes the winches to speed up too slowly, which causes the SLA to reach its end of stroke.

Simulations have been used to determine the minimum amount of damping necessary for the SLA to operate successfully in the integrated LARS configuration. However, damping was difficult to measure directly during the qualification test. Nevertheless, the effect of damping was observed readily by measuring the reduction in cart velocity from the beginning to end of stroke of the SLA.

Additional simulations have been performed to determine the expected performance of the SLA in the test setup used by the qualification test. In these simulations, a reduction of the cart velocity by $2 \mathrm{ft} / \mathrm{s}$ was typically achieved. This is the basis for the above requirement.

\section{SLA Tuning}

During initial testing, the performance of the SLA was significantly under-damped and the velocity of the SLA cylinder was oscillating. This was due to insufficient hydraulic damping, that is, insufficient resistance to the fluid flow through the hydraulic piping of the SLA. The performance of the SLA was tuned to the correct level of damping by inserting orifice plates with different orifice sizes into the hydraulic fluid path until a suitable level of damping was identified. The orifice plate with a $5 / 8 \mathrm{in}$ orifice provided the best results. This orifice plate was then added to the SLA design.

\section{E. Test Results}

After the SLA was properly tuned, a final test was performed. The results from this test show that the maximum logged cable tension was $27,420 l b f$, the maximum logged rod-end pressure was 1,915 psi, and the cart velocity was reduced by $2.6 \mathrm{ft} / \mathrm{s}$ from $12.2 \mathrm{ft} / \mathrm{s}$ to $9.6 \mathrm{ft} / \mathrm{s}$. The requirement was for the cable tension to be below 54, $265 \mathrm{lbf}$, the rodend pressure to be below $3000 \mathrm{psi}$, and the velocity reduction to be above $2 \mathrm{ft} / \mathrm{s}$. This demonstrates that the dynamic simulation of the SLA adequately corresponds to its actual performance and that the SLA successfully mitigates potential snap loads as a result of failures in the heave compensation system.

\section{CONCLUSION}

This paper has described the design and testing of a backup system to mitigate snap loads on a launch and recovery system. This is a novel design that depends on the tight coordination of the dynamics of the SLAs and the rendering function of the lift winches. The paper focused on the SLA concept and on the rationale for many design choices. Computer simulations were used both to illustrate the problem and to demonstrate the success of the solution. Hardware testing was performed to qualify the SLA design and to corroborate the computer simulations.

\section{REFERENCES}

[1] A. Huster, "SRS dynamic system model," Oceanworks International Corp., http://www.oceanworks.com/, Technical Report 0499-CA2300006, Rev A, November 2006.

[2] — , "LARS active motion compensation algorithm design," Oceanworks International Corp., http://www.oceanworks.com/, Technical Report 0499. CA23-00005, Rev A, November 2006.

[3] — "LARS snap load alleviator dynamics report," Oceanworks International Corp., http://www.oceanworks.com/, Technical Report 0499-CA2300007, Rev A, October 2006. 